\title{
Combination of cyclophosphamide and interferon- $\beta$ halts progression in patients with rapidly transitional multiple sclerosis
}

\author{
F Patti, M L Cataldi, F Nicoletti, E Reggio, A Nicoletti, A Reggio
}

\begin{abstract}
The effects of combined treatment with cyclophosphamide (CTX) and interferon- $\beta$ (IFN- $\beta$ ) are described in selected patients with "rapidly transitional" multiple sclerosis. This form of multiple sclerosis is extremely active with very frequent and severe attacks which produce a dramatic increase on the expanded disability status scale (EDSS). Ten patients with rapidly transitional multiple sclerosis were previously treated with interferon- $\beta$, but none benefited by this treatment. Monthly treatment with intravenous CTX, from $500 \mathrm{mg} / \mathrm{m}^{2}$ to 1500 $\mathrm{mg} / \mathrm{m}^{2}$ to obtain a chronic lymphocytopenia $\left(600 / \mathrm{mm}^{3}\right.$ to $\left.900 / \mathrm{mm}^{3}\right)$ produced a marked and significant reduction in the number of relapses $(p<0.0001)$, disability previously accumulated $(p<0.0001)$, and a reduction of T2 MRI burden of lesion. This particular group of patients benefited by combining cyclophosphamide and IFN- $\beta$. The possibility is considered of carrying out further studies to test the efficacy of the association between the two drugs for patients who are not responsive to IFN- $\beta$ or other active disease modifying therapies.

(F Neurol Neurosurg Psychiatry 2001;71:404-407)
\end{abstract}

Department of

Neurological Sciences, University of Catania,

Via S Sofia 78, 95123

Catania, Italy

F Patti

M L Cataldi

E Reggio

A Nicoletti

A Reggio

Institute of

Microbiology,

University of Milano,

Italy

F Nicoletti

Correspondence to: Dr F Patti

patti@mbox.unict.it

Received 12 September 2000 and in final form

5 April 2001

Accepted 9 April 2001

Keywords: multiple sclerosis; interferon- $\beta$; cyclophosphamide

Several studies have shown that IFN- $\beta$ and glatiramer acetate are active drugs able to modify the disease course of multiple sclerosis, with a global $30 \%$ decrease in the relapse rate in treated patients compared with placebo. Based on the limited clinical efficacy of both IFN- $\beta$ and glatiramer acetate other drugs have been proposed for experimental treatment in multiple sclerosis (mitoxantrone, azathioprine, fusidate, etc). Combination therapy could improve the control of the disease process.

None of these drugs is definitely active in modifying the course of the disease and the results are controversial. Among the different forms of disease, Weinstock-Guttman et al described a category of patients with very active relapsing-remitting multiple sclerosis, rapidly changing to progressive multiple sclerosis. This type of disease was characterised by an early and rapid worsening of disability (with at least 1.5 worsening points at expanded disability status scale (EDSS) evaluation in 6 months), which did not recover after common therapies (methylprednisolone). This form of the disease was defined as "rapidly transitional".

Recently Goodkin ${ }^{2}$ stated that the association of two or more drugs may represent the most suitable therapy choice for the treatment of patients who did not benefit by either interferon or glatiramer treatments.

Cyclophosphamide (CTX) is a cytotoxic immunosuppressive drug (alkylating agent). It was used in patients with multiple sclerosis in association with methylprednisolone in both chronic progressive and relapsing-remitting disease. The dose, the route of administration, and the duration of the treatment varied in the different studies and the results were controversial. ${ }^{3}$ In a few studies benefits lasted some months. ${ }^{45}$

The aim of this open study was to evaluate the effects of CTX given in association with IFN- $\beta$ to patients with rapidly transitional multiple sclerosis who were not responsive to IFN- $\beta$ alone.

\section{Patients and methods}

We selected 10 patients (six women and four men) affected by clinically definite rapidly transitional multiple sclerosis. The mean age was 24.9 (range 20-28), onset age 21.3 (range 17-24), and mean duration of disease 3.6 years (range 3-5). Relapses occurred in all patients with high frequency and the remission time from each relapse was not easily detectable because of the marked and rapid accumulation of disability. Rarely, a short phase of apparent clinical stability was evident between the succeeding relapses. In our patients a relapse was detected when a new symptom lasting more than 24 hours and causing handicapped sequellae occurred. All of these patients had started to receive IFN- $\beta$ (six with Avonex and four with Betaferon) within 1 year of the diagnosis of the disease. At the run in mean EDSS was 4.8 and the mean MRI total burden of the 
Table 1 Clinical findings and results

\begin{tabular}{|c|c|c|c|c|c|c|c|c|c|}
\hline Patient & Sex/age & Age at onset & $\begin{array}{l}\text { EDSS/months } \\
\text { Pre-IFN }\end{array}$ & $\begin{array}{l}\text { EDSS/months } \\
\text { IFN }\end{array}$ & $\begin{array}{l}\text { EDSS/months } \\
I F N+C T X\end{array}$ & $\begin{array}{l}\text { Relapse rate in } \\
\text { IFN/ } \\
I F N+C T X \\
\text { period }\end{array}$ & $\begin{array}{l}\text { MRI pre-IFN } \\
\left(\mathrm{cm}^{2}\right) \text { (No of } \\
\text { lesions) }\end{array}$ & $\begin{array}{l}\text { MRI IFN } \\
\left(\mathrm{cm}^{2}\right) \text { (No of } \\
\text { lesions) }\end{array}$ & $\begin{array}{l}\text { MRI } \\
\text { IFN+CTX } \\
\left(\mathrm{cm}^{2}\right) \text { (No of } \\
\text { lesions) }\end{array}$ \\
\hline 1 & $F / 24$ & 21 & A $3.0 / 11$ & $4.5 / 13$ & $2.5 / 18$ & $3 / 0$ & $41(23)$ & $67(38)$ & $55(33)$ \\
\hline 2 & $F / 23$ & 20 & A $2.5 / 12$ & $4.0 / 13$ & $2.0 / 18$ & $4 / 0$ & $23(9)$ & $49(21)$ & 41 (18) \\
\hline 3 & $M / 26$ & 23 & A $3.0 / 12$ & $5.5 / 13$ & $2.5 / 18$ & $4 / 0$ & $25(14)$ & $53(29)$ & 34 (19) \\
\hline 4 & $\mathrm{~F} / 20$ & 17 & A $2.5 / 09$ & $4.0 / 12$ & $1.5 / 18$ & $5 / 1$ & 29 (18) & $46(27)$ & $38(25)$ \\
\hline 5 & $F / 28$ & 24 & A $2.5 / 12$ & $4.0 / 14$ & $1.5 / 18$ & $3 / 0$ & $18(10)$ & $39(17)$ & $24(13)$ \\
\hline 6 & $\mathrm{M} / 27$ & 24 & A $3.0 / 11$ & $5.0 / 12$ & $2.5 / 18$ & $5 / 0$ & $43(18)$ & $70(36)$ & $48(27)$ \\
\hline 7 & $\mathrm{M} / 27$ & 23 & B $3.5 / 12$ & $4.5 / 13$ & $2.0 / 18$ & $3 / 0$ & $52(21)$ & 78 (35) & $59(26)$ \\
\hline 8 & $\mathrm{~F} / 22$ & 19 & B $3.5 / 11$ & $5.0 / 12$ & $2.0 / 18$ & $5 / 1$ & $35(15)$ & $61(28)$ & $42(20)$ \\
\hline 9 & $\mathrm{M} / 26$ & 21 & B $3.5 / 12$ & $5.5 / 16$ & $2.5 / 18$ & $4 / 0$ & $31(16)$ & $47(26)$ & $37(22)$ \\
\hline 10 & $F / 26$ & 21 & B $3.0 / 12$ & $6.0 / 15$ & $3.0 / 18$ & $4 / 0$ & $23(12)$ & $50(24)$ & $32(16)$ \\
\hline $\begin{array}{l}\text { Mean } \\
\quad(\mathrm{SD})\end{array}$ & $\begin{array}{l}6 \mathrm{~F}-4 \mathrm{M} / 24.9 \\
(2.55)\end{array}$ & $21.3(2.26)$ & $\begin{array}{l}3.0 \\
(0.40) / 11.4 \\
P R=0.8\end{array}$ & $\begin{array}{l}4.8 \\
(0.71) / 13.3 \\
\mathrm{PR}=1.6\end{array}$ & $\begin{array}{l}2.2 \\
(0.48) / 18^{\star \star \star}\end{array}$ & $\begin{array}{l}4 \\
(0.82) / 0.2^{\star \star \star}\end{array}$ & $32(10.68)$ & $56(12.42)$ & $41(10.61)^{\star \star}$ \\
\hline
\end{tabular}

${ }^{\star \star} \mathrm{p}<0.001 ;{ }^{\star \star \star} \mathrm{p}<0.0001$ (ANOVA). A=Avonex; $\mathrm{B}=$ Betaferon; $\mathrm{PR}=$ progression rate.

lesion was $56 \mathrm{~cm}^{2}$ (obtained with the Ormerod $\left.\operatorname{method}^{6}\right)$.

The relapse rate was 4 during the early phase and 4 during the prestudy time (IFN period). Progression rate of the disease was calculated: it was 0.8 during the pre-IFN period and of 1.6 during the IFN period, suggesting a poor response to IFN- $\beta$ treatment. All of the relapses were treated with methylprednisolone $(1 \mathrm{~g} /$ day intravenously for 6 consecutive days followed by a rapid 5 day oral prednisone taper (table 1).

EXCLUSION CRITERIA

Exclusion criteria were (1) concomitant diseases (liver, renal, lung, cardiac failures); (2) infectious and blood diseases; (3) other neurological or psychiatric diseases; (4) pregnancy.

CLINICAL EXAMINATION

All patients underwent a complete physical examination every month. determination of the EDSS with the support of functional systems scores (FSS) was performed by a senior neurologist. Blood and urine samples were collected and analysed every day during CTX administration and then every week for the 18 months of treatment. All patients had radiography of the chest at the beginning of the study and every 6 months during the study period.

Brain MRI was obtained by each patient at the early phase, at the prestudy period, and at the end of the study with a fast spin echo: GE $1.5 \mathrm{~T}$ Sigma scanner, $\mathrm{TR}=2500 \mathrm{~ms}, \mathrm{TE}=18$ $\mathrm{ms} / 90 \mathrm{~ms}$. Serial scans were obtained in the transverse plane from the level of the foramen magnum to the vertex. Exactly the same positioning and imaging sequences were used for all patients.

THERAPY

the CTX was intravenously administered from a dose of $500 \mathrm{mg} / \mathrm{m}^{2}$ to $1500 \mathrm{mg} / \mathrm{m}^{2}$ within 3 consecutive days on a monthly basis for 12 consecutive months so as to obtain a chronic reduction of lymphocytes $\left(600 \mathrm{~mm}^{3}\right.$ to $900 /$ $\mathrm{mm}^{3}$ ). At the end of the first year of treatment CTX was administered every 60 days for a further 6 months (at months 14, 16, and 18). Ondansetron was administered intravenously to all patients at a dose of $8 \mathrm{mg} /$ day just before CTX administration. Large volumes of fluids were administered intravenously on the day of treatment.

In association with CTX, all patients continued to receive regularly the previously established therapeutical regimen of IFN- $\beta$ - that is, Avonex at a dose of 6 MIU once a week (intramuscularly injected) or Betaferon at a dose of 8 MIU every other day (subcutaneously injected).

\section{STATISTICAL ANALYSIS}

Analysis of variance (ANOVA) was performed for the analysis of EDSS, relapse rate and T2 MRI burden of lesion changes which occurred after CTX and IFN- $\beta$ therapy. Pearson's test was performed to correlate EDSS and MRI burden of lesion.

ETHICS

All patients were fully informed on the possible risks deriving from the association between IFN- $\beta$ and CTX. All of them gave their informed signed written consent before starting CTX associated treatment.

\section{Results}

During the study period a marked decrease of the relapse number (mean $0.2(\mathrm{p}<0.0001))$ and a significant reduction of EDSS, with a mean value of $2.2(\mathrm{p}<0.0001)$, were found. Also T2 MRI burden of lesion significantly decreased (table 1). A marked reduction in lesion number on T2 images as well as a clear reduction of the lesion area occurred in five of 10 patients.

No significant correlation was found between EDSS and MRI burden of lesion at the end of treatment (data not shown).

At the end of the study all patients continued treatment with only IFN- $\beta$ (either Betaferon or Avonex). A further clinical evaluation (FSS and EDSS determination) was performed 1 year after the end of this study. The EDSS was stable in all patients and relapses occurred with very low frequency (two events in the whole group). Only one of the two relapses needed steroid therapy.

SIDE EFFECTS

In the first months of treatment side effects were rare and mild. Leukopenia and nausea often occurred; however, with lower frequency compared with previous reports. ${ }^{7}$ In only one 
patient a mild neuropathy related to CTX administration was found. Tendon reflexes reappeared 10 months after the discontinuation of CTX . To prevent bladder toxicity, large volumes of fluids were administered intravenously on the same day of the CTX injection. No haemorrhagic cystitis was seen.

\section{Discussion}

This study shows that a combination of CTX and IFN- $\beta$ is able to halt the progression of disability and reduce MRI burden of lesion in "rapidly transitional" multiple sclerosis. McAlpine had previously described a different form of transitional multiple sclerosis. ${ }^{8} \mathrm{He}$ reported a progressive course of multiple sclerosis after one isolated bout. WeistockGuttman et al defined the "rapidly transitional" form of multiple sclerosis. ${ }^{1}$ Our patients presented clinical features similar to those described by these authors.

Several lines of evidence show that the association between CTX and IFN- $\beta$ might improve the clinical profile of patients with rapidly transitional multiple sclerosis. Benefits from the association between these two drugs may depend on the effects of both drugs on the immune system. The reduction of lesion number and burden of lesion (table 1) may indicate a remyelination process. However no significant correlation was found between EDSS and MRI results.

Treatment with CTX reduces both blood and CSF $\mathrm{T}$ lymphocytes (changing the CD4/ CD8 ratio). ${ }^{9}$ It induces a shift of T1 lymphocytes towards T2 lymphocytes, ${ }^{10}{ }^{11}$ reducing the proinflammatory cytokines (interleukin (IL-1)), IL2, IFN- $\gamma$, and IL12) ${ }^{10}{ }^{12}$ and increasing the anti-inflammatory cytokines (IL4, TGF- $\beta$, IL6, and IL10). ${ }^{10-12}$ All of these modifications returned slowly to normal values a few months after the interruption of CTX administration. ${ }^{13}$ On the contrary, other evidence showed that the effects of CTX may last a few years after withdrawal. ${ }^{9}{ }^{14}$

It has recently been shown that CTX administration is able to slow progression of disability and reduce the accumulating burden of disease. ${ }^{15}$ These results become more evident when CTX is given to younger patients with a short duration of disease. ${ }^{16}{ }^{17}$

We hypothesise that rapidly transitional multiple sclerosis might be due to an overactivation of some lymphocyte clones, mainly active in pathological processes of central white matter. The chronic reduction of $\mathrm{T}$ lymphocytes to around $600 \times \mathrm{mm}^{3}$ could reduce the proinflammatory activation of cells and cytokines which are increased in this specific form of disease.

The clinical effects of decrease with time (benefits are uncertain after 18 months), ${ }^{18}$ although previous results obtained in patients with chronic progressive multiple sclerosis showed that the positive effects of the treatment were still detectable after 3 years. ${ }^{14}$

In our study, combining therapy for a period of 18 months brings the positive effects of this treatment up to 30 months.
The clinical improvement noted with the reduction of EDSS could indirectly account for the marked depression of white matter inflammation and sparing of axons from irreversible damage ${ }^{19}$ which otherwise would be present in these patients. Spontaneous restorative processes could occur with higher frequency in these patients. ${ }^{20}$

The association of IFN- $\beta$ with CTX seemed safe, although previous studies showed that both drugs may produce many side effects. ${ }^{71}$

\section{Conclusions}

This study, despite the limits of the design (not blinded and without controls, no previous CTX association) and of the limited sample number, suggests the utility of associating CTX with IFN- $\beta$ in accurately selected patients who exhibit a rapid and severe worsening of their disability. This association could be maintained for brief period. Our results demonstrate that IFN- $\beta$ treatment may contribute to the reduction in disease worsening also after the discontinuation of CTX boosters.

We think that the correct selection of patients represents the main point of this pilot observational study.

In conclusion, this study, within its limits, suggests that in patients with rapidly worsening multiple sclerosis, not responsive to the best common therapies, the association of CTX plus IFN- $\beta$ is amenable, safe, and to be recommended.

1 Weinstock-Guttman B, Kinkel RP, Cohen JA, et al. Treatment of "transitional MS" with cyclophosphamide and methyl-prednisolone (CTX-MP) followed by interferon- $\beta$ [abstract]. Neurology 1997;48(suppl 2):A341.

2 Goodkin DE. Interferon beta therapy for multiple sclerosis. Lancet 1998;352:1486-7.

3 The Canadian cooperative trial of cyclophosphamide and plasma-exchange in progressive multiple sclerosis. The Canadian Cooperative Multiple Sclerosis Study Group. Lancet 1991;337:441-6.

4 Weiner HL, Dau PC, Khatri B, et al. Doulble-blind study of true $v$ sham plasma-exchange in patients treated with immunosuppression for acute attacks of multiple sclerosis. immunosuppression for ac

5 Gonsette RE. Introductory remarks: immunosoppressive and immunomodulating drugs, where and how do they act? and immunomodulating drug

6 Ormerod IE, Miller DH, McDonald WI, et al. The role of NMR imaging in the assessment of multiple sclerosis and solated neurological lesions. A quantitative study. Brain 1987;110:1579-616.

7 Myers LW, Fahey JL, Moody DJ, et al. Cyclophosphamide "pulse" in chronic progressive multiple sclerosis. Arch Neurol 1987;44:828-32.

8 McAlpine D. Course and prognosis of multiple sclerosis. In: McAlpin D, Compston ND, Lumsden CE, eds. Multiple sclerosis. Edinburgh: Livingstone, 1955:135-55.

9 Uitdehaag BMJ, Nillesen WM, Hommes OR. Long-lasting effects of cyclophosphamide on lymphocytes in peripheral

10 Comabella M, Balashov K, Issazadeh S, et al. Elevated interleukin-12 in progressive multiple sclerosis correlates with disease activity and is normalized by pulse cyclophoswith disease activity and is normalized by pulse cy

11 Takashima H, Smith DR, Fukara H, et al. Pulse cyclophosTakashima $\mathrm{H}$, Smith $\mathrm{DR}$, Fukara $\mathrm{H}$, et al. Pulse cyclophos-
phamide plus methylprednisolone induces myelin-antigen specific IL-4 secreting T cells in multiple sclerosis patients. Clin Immunol Immunopathol 1998;88:28-34.

2 Bryniarski K, Ptak M, Ptak W. The in vivo and in vitro effects of an alkylating agent, mechlorethamine, on IL-6 production in mice and a role of macrophages. Immunopharmacology 1996;34:73-8.

13 Moody DJ, Fahey JL, Grable E, et al. Administration of monthly pulses of cyclophosphamide in multiple sclerosis patients. Delayed recovery of several immune parameters following discontinuation of long-term cyclophosphamide treatment. F Neuroimmunol 1987;14:175-82.

14 Hommes OR, Prick JJ, Lamers KJ. Treatment of the chronic progressive form of multiple sclerosis with a combination of cyclophosphamide and prednisone. Clin Neurol Neurosurg 1975;78:59-72.

15 Gobbini MI, Smith ME, Richert ND, et al. Effect on open label pulse cyclophosphamide therapy on MRI measures of 
disease activity in five patients with refractory relapsingdisease activity in five patients with refractory relapsing16 Weiner HL, Mackin GA, Orav EJ, et al. Intermittent cyclophosphamide pulse therapy in progressive multiple sclerosis: final report of the Northeast Cooperative Multiple Sclerosis Treatment Group. Neurology 1993;43: 910-18.

17 Hohol Mj, Olek MJ, Orav EJ, et al. Treatment of progressive multiple sclerosis with pulse cyclophosphamide/ methylprednisolone: response to therapy is linked to the duration of progressive disease. Mult Scler 1999;5:403-9.

18 Goodkin DE, Plencner S, Palmer-Saxerud J, et al. Cyclophosphamide in chronic progressive multiple sclero- sis. Manteinance $v$ non-manteinance therapy. Arch Neurol $1987 ; 44: 823-7$.

19 Trapp BD, Peterson J, Ransohoff RM, et al. Axonal transection in the lesions of multiple sclerosis. N Engl F Med 1998; 338:278-85.

20 Storch M, Lassmann H. Pathology and pathogenesis of demyelinating diseases. Curr Opin Neurology 1997;10:186-

21 Weber F, Polak T, Gunther A, et al. Synergistic immunomodulatory effects of interferon- $\beta 1 \mathrm{~b}$ and phosphodiesterase inhibitor pentoxifylline in patients with relapsingremitting multiple sclerosis. Ann Neurol 1998;44:27-34.

\section{NEUROLOGICAL STAMP}

\section{Willem Einthoven (1860-1927)}

Einthoven's lifetime work was dedicated to electrocardiography and its extended applications. He qualified in 1885, and in the same year was appointed professor of physiology at Leiden where he worked until his death. For his development of the electrocardiogram he was awarded the 1924 Nobel Prize for physiology or medicine.

He entered the University of Utrecht in 1878, planning to specialise in ophthalmology and to follow his father into the army and colonial medical services. At Utrecht at the Gasthuis voor Doglijders, a famous eye hospital, he worked with FC Donders, a pioneer of ophthalmology, and also with the ophthalmologist $\mathrm{H}$ Snellen.

He wrote two papers as a student. The first was Some remarks on the elbow joint. This was a consequence of his fracturing his own wrist during a gymnastic exercise and was a study of pronation and supination of the arm. In the paper he analysed the anatomy of the arm according to the principles of mathematics and physics. His second paper Stereoscopy by means of colour variation arose from the work for his thesis.

In the late 1880 s he performed studies in asthma demonstrating its basis in bronchial spasm which he produced by stimulation of the vagal nerve with carbon dioxide. In 1883 he continued his studies in optics and recorded electrical potentials of the eye and later of the heart. In 1903 he constructed a string galvanometer with which he also recorded the reaction of the eye to light and electrical activity of vagal nerves. In his last experiment in 1927 he recorded the action potential of the sympathetic nerve.

The question was raised whether an instrument (his string galvanometer) should be honoured by a Nobel Prize in physiology or medicine, or physics. The decision to physiology or medicine was agreed after Einthoven's clarification that the galvanometer was fundamental to the recording of the electrocardiogram, and the clinical application produced very practical results.

Einthoven was honoured philatelically by Mexico in 1972 alongside an American cardiologist Dr Frank Wilson. The stamp also shows a mural by Diego Rivera. As well as Drs Wilson and Einthoven, the heads of Dr James Herrick (left bottom) and Dr Paul Dudley White (right bottom) are shown (Stanley Gibbons 1242, Scott C395).

L F HAAS 